OMEGA, Vol. 63(2) 141-160, 2011

\title{
COPING WITH THE ULTIMATE DEPRIVATION: NARRATIVE THEMES IN A PARENTAL BEREAVEMENT SUPPORT GROUP*
}

\author{
LAURA R. UMPHREY \\ Northern Arizona University, Flagstaff \\ JOANNE CACCIATORE \\ Arizona State University, Phoenix
}

\begin{abstract}
Support groups are often used to help individuals cope with challenging and unusual life circumstances through narration. Yet, little is known about specific meta-communication within a support group setting and in what ways these interactions may benefit participants. This study uncovers narrative themes that were expressed during a series of support group meetings specific to bereaved parents. Three central narratives were revealed in the analysis including the death story narrative, coping/negotiating narrative, and connecting through communication with others narrative. This research underscores the vital outlet that the support group serves for participants and the communicative means by which subjective healing can occur.
\end{abstract}

\section{INTRODUCTION}

The loss of a child is both untimely and tragic (Gudmundsdottir \& Chesla, 2006), and it is considered the greatest of all losses (Rosof, 1994). Humans form

*The authors are indebted to the 29 bereaved parents for allowing the presence of the first author at the support group meetings and for sharing their stories of loss and coping. In this report the names of participants and their children have been changed to protect their identity.

(c) 2011, Baywood Publishing Co., Inc. doi: 10.2190/OM.63.2.c

http://baywood.com 
emotional bonds with their children in the form of attachments (Bowlby, 1969; 1973) wherein parental identity is formed and reinforced (Katz-Wise, Priess, \& Hyde, 2010). Child death is, thus, considered the "ultimate deprivation" (Arnold \& Gemma, 1994, p. 40). The child may not be physically present but the parents are left with the contradiction that they are a parent without a child physically present to parent (Toller, 2005). This often incites ambiguous loss (Cacciatore, DeFrain, \& Jones, 2008) as parental identities, once deeply enmeshed in this symbiotic relationship, are dramatically altered and they are left to negotiate these new and unwelcomed roles (Toller, 2008).

Bereaved parents often have a need to talk about the deceased child and share their story with others (Cacciatore, 2007; Harvey, 1996). From a functional perspective, the sharing of stories serves several purposes. It allows for the bereaved parent to help make sense of the death in their search for meaning, thereby legitimizing the child's life (Cacciatore, 2007; Bosticco \& Thompson, 2005b; Keesee, Currier, \& Neimeyer, 2008). It validates, clarifies, and explains events that have happened (Bosticco \& Thompson, 2005b). It helps the bereaved learn to talk about the deceased with others, often acting as a catharsis (relieving of emotional tensions) (Bosticco \& Thompson, 2005b). It can give bereaved parents a sense of hope that they can function in life (Harvey, 1996).

Research suggests that having adequate support following the death of a child can help the grieving process (Riley, LaMontagne, Hepworth, \& Murphy, 2007). However, there is sufficient evidence to suggest that friends and family may not be effective at providing support, and that cultural proscriptions to suppress mourning may impede healing for some (Toller, 2005). Western society generally accepts a mourning period that includes attending a funeral or memorial to pay tribute to the child but public mourning of the deceased beyond the initial acknowledgment is less common and less accepted (Gudmundsdottir \& Chelsea, 2006). Friends and family often expect the grieving parent to experience a prompt recovery following the death, a return to "normal" (Stylianos \& Vachon, 1993). Often the socially accepted grieving period falls far short from the duration needed by the bereaved parent. As a result of the chasm between societal expectations and reality, bereaved parents may feel the need to modulate their grief around family and friends (Cluck \& Cline, 1986). This subtle pressure to silence the loss may inhibit the expression of grief and compromise coping (Cluck \& Cline, 1986). Many bereaved parents find it difficult to talk with others following the death of a child (Toller, 2005), particularly beyond the acute phase of bereavement. As a result of this, some may feel alienated from others, particularly if the loss is stigmatized such as with AIDS, suicide, or perinatal death (Cacciatore, Schnebly, \& Froen, 2009; Cluck \& Cline, 1986). Ultimately, the unique and interminable needs of bereaved parents are rarely met with just family and friends (Cluck \& Cline, 1986). Provided that a bereaved parent's natural support system may often be insufficient to meet their needs, and societal expectations hasten and misunderstand grieving parents, other sources of support are needed. This 
feeling of aloneness and isolation (Riches \& Dawson, 1996) has given rise to many grassroots support groups for bereaved parents in the past two decades.

\section{RESEARCH ON BEREAVEMENT SUPPORT GROUPS}

Previous research on support group participation has examined predictors of participation in support groups (Levy \& Derby, 1992; Picton, Cooper, Close, $\&$ Tobin, 2001). These predictors include perceived stigmatization of joining a bereavement support group (Bambauer \& Prigerson, 2006; Levy \& Derby, 1992) and perceived need for emotional and social support (Picton, Cooper, Close, $\&$ Tobin, 2001).

Bereavement support groups have been correlated with a number of psychosocial outcomes such as declines in stress and depression (Levy, Derby, \& Martinkowski, 1993; Reif, Patton, \& Gold, 1995), diminished traumatic grief reactions, particularly in women (Cacciatore, 2007; Maruyama \& Atencio, 2008), resilience through meaning and purpose (Murphy, Johnson, \& Lohan, 2003), and reduced feelings of isolation (Tedeschi \& Calhoun, 1993). Overall, participation is associated with positive effects on mental health (Mitchell, Gale, Garand, \& Wesner, 2003).

Most of the research specifically on bereaved parents has been conducted using interviews with parents (Bosticco \& Thompson, 2005b; Gudmundsdottir \& Chesla, 2006; Riches \& Dawson, 1996; Toller, 2005, 2008), surveys (Barrera et al., 2007; Cacciatore, 2007; Kamm \& Vandenberg, 2001; Keesee, Currier, \& Neimeyer, 2008; Murphy, Johnson, \& Lohan, 2003; Riley, LaMontagne, Hepworth, \& Murphy, 2007) or analyses of websites or online forums (Hastings, Musambira, \& Hoover, 2007; Musambira, Hastings, \& Hoover, 2006). Only a few studies of parental bereavement support groups have been conducted. Two of the studies were cross-sectional analyses of different types of support groups that included bereaved parents in the analysis and were not specific analyses of parental bereavement groups (Hopmeyer \& Werk, 1994; Thuen, 1995). One study of parental bereavement support groups examined the outcomes of a time-limited, hospital-based support group designed for parents who had children who died in a neonatal intensive care unit (Reilly-Smorawski, Armstrong, \& Catlin, 2002). Perhaps the most extensive programmatic research using data from a Compassionate Friends parental bereavement support group uncovered the many psychological and social changes that bereaved parents experience during their grief (Klass, 1988, 1993, 1997, 1999). However, while data was collected in this support group context, the details of the structure and format of group meetings were limited. Given the rich communicative context that support groups have to offer, it is surprising that more research has not been conducted in this environment. The present research extends previous research by examining the structure, format, and narratives revealed in a parental bereavement support group. Narratives provide a window for understanding the unique 
experiences faced by bereaved parents and the support group is a natural setting for this to take place.

\section{Research Questions}

Based on the review of literature the following research questions were posed:

1. What is the process and development of self-help groups for bereaved parents?

2. What are the central narratives or themes that are shared among participants?

\section{METHOD}

\section{Observations of Group Meetings}

This research was granted IRB approval. Permission for the study was granted by the MISS Foundation Board of Directors. The MISS Foundation, an international organization that provides support to families experiencing the death or impending death of a child, was founded in 1996 in Phoenix, Arizona. It has since grown to more than 76 chapters around the globe, including chapters in Paraguay, Romania, and Mexico. The MISS Foundation offers a variety of services to families, including counseling, advocacy, research, and education. Support groups are facilitated by trained para-professionals, and HOPE (Helping Other Parents Endure) mentors; grieving parents and grandparents who are at least 18 months into the bereavement process. As they shepherd newly bereaved parents they are often matched according to geographic location, child's age, and cause of death. The MISS Foundation also has a busy online presence with 27 support forums and thousands of active members. The support forums provide 24-hour fellowship with like-others, and specific boards include fathers only, pediatric hospice, Spanish-speaking, and siblings groups.

\section{Participants}

Participants in this study were parents attending a MISS Foundation parental bereavement support group in a large city in the southwest. The meetings are scheduled on a monthly basis, are free to any bereaved parent, and are open meetings. That is, there is no attendance or enrollment requirement.

Over the span of the study there were between $12-15$ bereaved parents attending each meeting (not including the facilitators). There was a total of 29 bereaved parents who participated in the group over the five month period. On average, between four to six couples attended each meeting. The gender of participants varied such that at one meeting there were four males and nine females and at another meeting there were six males and seven females. The cause of death for the deceased children include nine babies who died from stillbirth (3) or in the 
perinatal period (6), two who died from accidents (drowning, motor vehicle), five died from unexplained causes or Sudden Infant Death Syndrome, two died from suicide, two died from complications with a medical problem (disease and surgery), and three died as a result of congenital anomalies incompatible with life.

In terms of consistency, two couples attended each of the five meetings. Other participants attended the meetings between one to four sessions. The parents whose child died from suicide only attended one meeting. Some evenings only one parent attended the meeting and other nights they attended as a couple. One Spanish-speaking couple attended only one meeting. For those who attended one or two meetings, many of them were the spouse of someone who attended regularly. In two instances, the bereaved moms were pregnant and missed meetings due to the pregnancy and other family obligations. Three males reported that work obligations kept them away from the group.

\section{Before the Research}

Both principal investigators of this research are bereaved parents. The primary author's daughter died in 2005 at the age of 2 years 11 months after a 24-day battle with RSV/pneumonia. She started attending hospice-sponsored parental bereavement support group meetings solely as a participant for several years before deciding to conduct research on these types of groups. The second investigator is a researcher and therapist for the bereaved. She has been facilitating bereavement support group meetings for more than 14 years. Neither of the authors were a member or facilitator of the group being analyzed.

\section{Data Collection}

The first principal investigator attended five parental support group meetings over the span of 6 months. Observations and notes were made before, during, and after the meetings. Observations were recorded immediately following each meeting through a combination of audio-recorded descriptions that were subsequently transcribed or direct field notes. Extreme care was taken to ensure that statements of significance made during the meeting were accurately transcribed. The final compilation of observations resulted in 51 pages of single-spaced field notes.

\section{Grounded Methodology}

This qualitative research involved participant observation of a series of MISS Foundation bereaved parents support group meetings. This participantobservation methodology gives the researchers a primary data source, and concepts that emerge from the data gain provisional acceptance until they are verified against data from the literature (Wright, 1997). Following a grounded approach, this study used a thematic analysis of the field notes (Corbin \& Strauss, 
1990; Strauss \& Corbin, 1994) to understand both the process and development and central narratives and themes that emerge. In addition, a constant comparative method was used on the data. The constant comparative method of analysis consists of going back and forth from the original field notes to the words, concepts, and emergent themes, constantly checking and revising the interpretation as needed (Glaser \& Strauss, 1967). Basic to the method is reading and rereading the field notes, becoming immersed in the meaning structures and themes, having incubating time to think and reflect, verifying the themes that occur over time, and re-examining the conditions, contexts, and implied consequences presented by the text, thus confirming the substance of and relationships among themes and subthemes (Colvin, Chenoweth, Bold, \& Harding, 2004).

The stages in the grounded approach involved assigning conceptual labels to data and generating categories and properties, integrating categories and their properties, delimiting the themes, and creating thick and rich descriptions of the emerging themes.

The process of arriving at conceptual labels involved discovering and labeling concepts (such as discrete happenings and events) in the field notes. This phase of the analysis is called open coding (Glaser \& Strauss, 1967; Strauss \& Corbin, 1998). Once concepts were identified, the researcher created higher order categories. Initially there were 270 initial concepts presented. This stage of the process involves the making of comparisons between like categories and asking questions. These higher order categories were described in terms of their properties and dimensions. Code notes were then created based on the direct analysis and markings on field notes.

The second phase of analysis involved taking one category at a time and reading and re-reading the code notes and refining them into emerging themes. Each statement was constantly compared to the identified themes to determine whether they represented those themes or whether new themes were needed. Through this process, statements were rearranged and themes were both expanded and reduced. Initially there were nine broad categories revealed in the data. These categories were broadly named: negotiating emotions, trigger moments, keeping the memory alive, coping, influences on family decisions, communicating with others, what happened, the importance of talk, and "why me?"

The third stage of analysis, selective coding, is the process of arriving at core categories. The process of arriving at the core categories involves explicating the story line, relating subsidiary categories around the core categories, relating categories at the dimensional level, validating relationships against the data, and filling in categories that may need better explication (Strauss \& Corbin, 1990). This process continued until no new codes or categories emerged and the data were all accounted for (Glaser \& Strauss, 1967; Strauss \& Corbin, 1998).

Once no new codes or categories emerged, the focus of analysis moved to delimiting the themes. This process involved clarifying the logic, removing non-relevant properties, and integrating and elaborating details of properties to 
arrive at a refined classification of emergent themes. The nine themes collapsed into three dominant themes called the death narrative, coping/negotiating narrative, and the communicating with others narrative. The researchers began to write the text describing these three emergent themes. In addition, the researchers then analyzed the framework that emerged from the data in relation to the literature. "Concepts that have been repeatedly verified by the data are brought in as support for concepts in the literature" (Wright, 1997, p. 89).

\section{RESULTS}

\section{Support Group Procedures}

The process of conducting a bereavement support group proceeds in several phases. The meeting is approximately 2 hours and is held once per month. Initially the facilitator sets the stage for the interaction by organizing the seating, placing supplies such as tissues and snacks, and organizing pamphlets and brochures that parents may peruse. The seating arrangement is in an oval shape without any physical barriers, such as tables, in the center. As parents arrive they take a seat in the circle and wait for the facilitator to begin the meeting. If parents have previously attended, they may know other parents in the group and may talk quietly. The facilitator is able to greet parents and assess their demeanor before the session begins. If there is a new person the facilitator makes a point to introduce herself, welcome the new person and orient them. Once parents are seated and the meeting time arrives, the facilitator has a monologue to present to the audience. She welcomes everyone to the meeting and begins with any announcements. Announcements are usually about MISS Foundation events in the local area. The facilitator then welcomes everyone, emphasizes the importance of confidentiality during meetings (she defines confidentiality), gives a brief overview of the MISS Foundation's mission, and invites someone to begin. If there are newly bereaved parents in the group, she will usually introduce herself and tell, briefly, her own story (all facilitators are bereaved parents). After someone starts telling his or her story, the meeting proceeds either clockwise or counterclockwise. The content of those stories are explained as themes later in this article. Once everyone has had a chance to speak, depending on time, the meeting is opened to a general discussion (for example, the November's meeting theme may center on how to manage grief during the holidays) or the group meeting is ended and parents are invited to mingle and talk.

\section{Bereavement Storytelling Themes}

There are three core narratives that are presented at this bereavement support group: a) the death story narrative, b) coping/negotiating narrative, and c) connecting with others through communicating narrative. Each of the three core narratives will be described in detail. 


\section{The Death Story}

The death narrative explains, sometimes in great detail, the circumstances surrounding the child's death. Bereaved parents usually begin with this story when they speak to the group. The narrative starts by revealing the number of children who have died and the date of birth and date of death of each child. The "death narrative" is a story of what circumstances led up to the death of the child. The death narrative may include a description of the event and the acute emotional, behavioral, and physiological responses. Parents almost always give a name to what caused the death (e.g., SIDS, traumatic birth, disease, accident, or suicide).

The range of detail provided in the death narrative by each parent varied. Some parents kept the death narrative very factual. These parents presented birth and death dates and briefly described the cause of death. For others, there was greater detail provided. Some people gave specific information about the moments before death. One woman described her son's death in such detail that she was crying while talking about it: "We thought we would have had more time with him. When the doctors took him off the ventilator he lived for less than 10 minutes. We were in the elevator with him as he took his last breath and rushed him out to the gardens at the hospital to be with him."

\section{Coping/Negotiating Narrative}

Often, the death narrative is followed by a self-assessment of coping. This is initially expressed in terms of whether it has been a "good month" versus "bad month." The distinction between good and bad may center on factors such as trigger moments (such as holidays or anniversaries), and the ability to function or adapt to this new reality by preserving the memory of the child and adapting life plans.

Trigger moments are moments in time when there is something that serves as a stimulus to bring back memories of the child. Often this stimulus will catch parents by surprise. It can be subtle events such as a change of seasons, familiar olfactory arousal, photographs, seeing a child's favorite toy, hearing a song, or passing through a certain location. An example of this was one parent who lost an only child in March and had the sharp reminder of "Mother's Day" the following month. Friends and relatives did not send Mother's Day cards that year, further spiraling the identity question of whether one is still a mother even when a child is deceased: "My daughter died in March. In May of that year, Mother's Day was particularly painful. My family didn't send cards when in the past they had. It made me wonder whether I was still considered a mother."

Anniversaries of birth and death dates are a particular challenge for bereaved parents. Many parents talked about the anticipation of the date. The newly bereaved do not know how they will react and are not sure what to do on that date. One dilemma that parents face is the degree to which the date is shared 
with "others." One couple threw a party for what would be their son's 4th birthday: "We invited friends and family and had a cake with a party theme that is currently popular with 4-year-old boys; Spongebob. Not many people showed up for the party. I asked the caterer what she thought of the party and she said it was the perfect number of people so that made me feel good." Other parents create new rituals as a way to negotiate painful days. On the anniversary of the death of her son, one parent writes a poem to her son that expresses how she is doing that year and what it is like to live without him. She revealed that this ritual serves to reduce the uncertainty of the date: "I know that every year I will be writing a poem and it makes it easier for me to anticipate the date." On the anniversary of her son's birthday, she does something nice for herself, such as a massage, and calls it a gift from her deceased son. The sharing of stories helps group members by giving them different perspectives on how to cope with the emotional distress incited by grief. It seemed particularly helpful to hear how other bereaved parents coped with anniversaries and holidays.

Another discussed "trigger" for parents is having friends who have children who share similar birthdates with the deceased children. This makes bereaved parents wonder what their child might look like or what might be their interests if the child was still alive. As one person stated, "For the rest of my life I will have friends whose children would be my daughter's age." She further revealed that it is hard to celebrate their milestones without the constant reminder of what she has lost. As another parent revealed to the group, "Other people's life events will unexpectedly affect yours."

Many parents revealed that they had a life-plan and the plan is not complete without their child. The death of a child represents a loss in parental identity, particularly if their only child died. This can influence future family plans. One couple, whose only daughter died from SIDS, stated, "She was our first child and we don't know if we want to have another." Another couple stated, "We planned everything and he was the biggest part of it. My plan is done but it's not complete."

The ability to function in the world is a challenge for many bereaved parents, especially if the death is recent. Daily activities that were once accomplished with ease are now potentially distressing. One father stated, "I pull into a gas station and I hear a country song and break down and I'm like why is this happening to me? Or I'll be at work and I will be changing tires and will start to think about it."

Parents indicated that they have a need to keep the memory of the deceased child alive and they accomplish this in various outreaching ways. Examples of this included creating a foundation in the name of the deceased child, having a toy drive, organizing a bike ride, erecting a local playground, or donating a rocking chair to a funeral home to help other grieving parents. More personal ways of remembering the deceased include displaying photos or scrapbooks and bringing photos to meetings, having celebrations or providing cupcakes at 
meetings on the deceased child's birthday, or journaling. In some instances, parents wear t-shirts or buttons bearing a photo of the child.

\section{Communicating with Others}

Very often, relating to others who have not lost a child is a challenge that parents must negotiate. In many instances, bereaved parents, willingly or unwillingly, lose friends and acquaintances because of insensitivity, miscommunication, or avoidance. One woman revealed, "No one talks to me anymore and I don't talk to others. Relatives call less. It's easier for them to not talk to a person who has lost a child." Bereaved parents also carefully calculate the appropriateness and risk of disclosure, aware of the possibility that others may respond in hurtful ways. The potential level of social support from others is evaluated before a bereaved parent will mention the deceased child's name in conversation. Many parents talked about being tired of "faking it" with others. This suggests that bereaved parents, while not only dealing with the grief of losing a child, have the added burden of pretense: "I keep my smile on but I am tired of faking it. I'm so far from being ok but I know where I can go when I'm not ok." Another person reiterated, "You can only fake it for so long." One parent revealed that her family wanted to know when the "old me" would come back: "My family wants to know when the old Jennifer is coming back. I told them that that person is gone." Another mother stated, "I told my husband and kids that I cannot be the same person that I was before but I can be someone different."

There is an expectation by others that bereaved parents should be "fine" by certain points in time. Bereaved parents are made aware of this expectation by others' responses to them. This normative expectation can create an isolating feeling for parents who are grieving. One parent revealed that her mother thought she should be in counseling since she was still "dealing with that" 3 months since the death of her child. Another parent stated that after four months co-workers are less willing to listen and he has heard the statement, "You're still dealing with that?" Other statements revealed by group members include "You should live happily with the two children that you have," or "We've all been through it." In this last statement the relative implied that they were experiencing the same grief as the parents of the deceased. One group member had a friend try to relate to her using the death of her grandparent; an experience she did not find helpful. She stated, "It's tough because others will compare the death of a grandparent to the death of a child. It's their way of trying to relate to someone who has lost a child but it's not the same." Overall, the sentiment was that other people who have not experienced the death of a child do not understand.

Additional topics of conversation focused on surviving and subsequent children as well as how to acknowledge the deceased children in the family count. Replacement children were mentioned several times. Parents talked about how family members would say things such as, "Well, now that May is a good month 
for you (due to the birth of another child), you don't need to be sad anymore." One group member talked about a subsequent pregnancy and how family members believed that having another baby would make things all better: "People thinking that if you have another baby that it is like a replacement baby and that you are all better. The new baby doesn't replace the other baby."

In interacting with others there is a tension with how to count the deceased child in the family. One parent who had seven children altogether, two of whom died, struggled with the conflict of telling a stranger that she has seven children. "I was in the grocery store and someone saw my children and asked if they were all mine. When I said yes he seemed surprised and followed up by asking how many children that I have. I told him seven and gave him the ages of my five living children. I told him that two had died. His response was, "So, you really only have five kids?" Another couple stated, "If anyone asks if we have children we make sure to say that we say two; one in heaven and one here. It doesn't matter that he is not with us. He still counts." One parent corrected her mother when she said that she had four grandchildren: "I had to correct my mom. She was telling someone that she had four grandchildren. I told her, 'No, you have five grandchildren. Just because Alex is not here doesn't mean that he doesn't count.' The children still count and they do matter."

In very subtle ways, the role of the group for parents was revealed through meta-communication (communicating about communication in the group). The experience in the group was usually contrasted with the experiences of communicating with people who have not lost a child. In several instances, participants talked about other bereaved parents in the group as "family" or even more like family than their biological family members. One group member revealed, "The group is more like family because I can't count on family members to get together even once a month but the group is always there for me."

The group also serves as a reminder that parents are not alone. Death remains a taboo subject in Western culture and sometimes it feels as though the parent is the only one facing this challenge. One group member expressed this sentiment with the following statement: "It's hard to stay positive but knowing that we're not alone is the ticket."

Group members also expressed gratitude to the group for being a place where they can feel understood, feel that what they are experiencing is normal, and parent the child that they can no longer parent: "What we have in common is that we have all loved and lost a child." Another revealing statement was, "You don't feel like an odd ball or crazy when you are around your friends in the group." Attending group meetings, for some, was a way to devote time to remembering the deceased child or to stay connected with the child: "It allows me to parent the child that is no longer here. Without that, she is just gone." 


\section{DISCUSSION}

From a theoretical standpoint, narratives play a central role in the discourse at a parental bereavement support group. The three major themes revealed were the death story narrative, the coping/negotiating narrative, and connecting with others through communication narrative (meta-communication). Some of these themes have appeared as important stories told by bereaved parents in previous research (Dyregrov \& Dyregrov, 2008; Graves, 2009; Klass, 1988, 1993, 1997, 1999; Rosenblatt, 2000). They now have been expanded by the current research on meta-communication within support groups. Graves (2009) describes conversations with bereaved parents in terms of elements. The elements of conversation from her perspective include the death story and the strategy for coping with the loss (Graves, 2009). This research also supports previous findings in terms of the importance of sharing experiences and learning new coping skills (Hopmeyer \& Werk, 1994). The third theme, communicating with others, is reflected in the literature on network support (Dyregrov \& Dyregrov, 2008). Klass $(1988,1997)$ suggests that the process of parental grief requires that a new equilibrium is established (a) within the self and (b) between the self and the social world. The present research provides further evidence of the psychic and social struggles parents have renegotiating the new reality without their children.

Through stories, individuals and groups reveal their perspective of the world to others (Foss, 1989). Stories contain characters, attitudes, and behaviors which take place in specific settings. Story-telling provides a venue for individuals to give their unique interpretation of a particular event and is a communicative expression of reality. Foss (1989) outlines three steps listeners use for understanding narratives. First, the narrative helps to explain the details of a story. In other words, the narrative should reveal the central theme or poignant actions taking place. Second, the narrative describes the central action but also ties the perspective of the storyteller's interpretation of the experience of that action (Foss, 1989). Third, people listening to stories will evaluate them to determine if they are consistent with their worldview. In other words, listeners decide if the interpretation presented is consistent with their perspective. Fisher (1984, 1987) calls this evaluation rationality. He argues that rationality is based on narrative probability (internal coherence of stories told), narrative fidelity (the correspondence with the listener's reality) and the good reason (underlying value or ethics) of our stories (Fisher, 1987). Good reason is based on the values implied in a message, how relevant the values are to previous decisions made, the congruity with listeners' values and how the listener thinks the narrator should behave (Griffin, 2009). Stories may change, evolving over time, and it is through the re-creation and reinterpretation where healing takes place.

A parent's search for meaning is heightened following the death of a child (Hastings, Musambira \& Hoover, 2007). The bereaved parent recounts stories of this life-altering event and attempts to process, understand, and find the 
meaning in the deceased person's life and death. Without the death narrative, the parental bereavement support group would not exist. Not surprising, the death narrative is the story that is told first to the group, if nowhere else, sharing details about the characters and circumstances of events that have taken place (Hasting, Musambira, \& Hoover, 2007). More specifically, it explains how the person died, precedent and antecedent factors, and when and how the narrator learned of the death (Bosticco \& Thompson, 2005a). The decision of how much depth to reveal in the death narrative may be regulated by whether the person telling the story can control their own emotions during the telling of such details.

A key element of importance: Crying during the meetings is uninterrupted and accepted as normal by participants. People within the group seemed to possess a mutual comfortableness with painful emotional expression. This is a tolerance that parents did not often experience outside the support group, even with their therapists. Emotions expressed ranged from anger, fear, and jealousy to sadness, regret, and guilt. At times these emotions could be overwhelming and at other times the bereaved parent felt the need to suppress emotions. As one parent stated, she is able to "put it on a shelf" and function when needed. In several instances, newer parents in the group questioned whether they will fully experience joy or laughter again as they did before the death. This is one area where it benefitted the newer attendees to see and hear from parents who are further along in the grief process.

In a bereaved parent's search for a "new normal," stories add coherence to events and help people comprehend reality. The role of the group in how a story is told and how meaning is changed is critical (Brockmeier \& Harre, 1997). One area of study that embodies the power of storytelling in a clinical setting is narrative therapy (Freedman \& Combs, 1996; Monk, Winslade, Crocket, \& Epston, 1997; Parry \& Doan, 1994). The metaphor of narrative is framed within a social constructionist worldview. The first assumption of this view is that humans are "prisoners of perceptions" of experiences (Pare, 1995). In other words, perceptions of reality are socially constructed and framed by previous experiences and learned cultural norms. It is through language that reality becomes constituted (Freedman \& Combs, 1996). "Language does not mirror nature; language creates the nature we know" (Anderson \& Goolishian, 1988, p. 378). Language use is a performance and when individuals speak, they are describing and therefore legitimizing their perceptions of reality. As such, stories become a central vehicle for organizing and maintaining perceptions of reality (Freedman \& Combs, 1996). People use stories in their attempt to make sense of an event that is nonsensical. In constructing stories, people try to arrive at a coherent account of their experiences, themselves and the world around them (Freedman \& Combs, 1996).

Another central assumption is that knowledge is co-constructed within communities of knowers (Pare, 1995). "The knowledge that we inhabit are those that we negotiate with one another" (Freedman \& Combs, 1996, p. 20). It is 
through discourse that new interpretations, and consequently perceptions, of reality are made. In the present research, shared story-telling helps bereaved parents learn new ways of talking about the death, handling facets of emotions, coping with their new reality, and talking with others. By hearing other people's challenges and strategies for managing them, other parents assess the degree to which they can relate to the story and whether they can or should assimilate it into their own story. This dialogue can transform perceptions and helps in the sense-making process. From the storyteller's perspective, the group structure helps members construct a bigger picture, helps them re-interpret their own stories, and supports them as they rethink their past and use it to mold their future (Graves, 2009).

Beyond shaping one's own reality, the group provides a sense of community for members. Friendships are created and relationships are maintained with continual participation in the group. Group members often meet outside of the group while participating in MISS Foundation sponsored community events. This natural extended social interaction with fellow support group members outside of the group setting provides an additional source of social support for bereaved (Caserta \& Lund, 1996).

Communication appeared to be a clear topic among participants. The distinction between communicating with group members and people who have not lost a child was clearly differentiated. Communicating with people who have not lost a child is a challenge that presents potential conflict on a daily basis for bereaved parents. The findings in the present study are consistent with previous research on dialectical tensions (Toller, 2005, 2008). In a study of bereaved parents, Toller (2008) found that parents feel stigmatized and isolated from others who impose their own pre-conceived rules about how a person should grieve. In order to protect themselves, bereaved parents limit the extent that they talk to "outsiders" and would rather seek the support of grieving "insiders" (Riches \& Dawson, 1996). Outsiders may not know what to say to a bereaved parent and they may end up ignoring or avoiding the parent (Bosticco \& Thompson, 2005b). One possible explanation is that the outsider does not have a script for interacting with others about death. Scripts are unconscious expectations that shape communication in a well-understood situation (Bosticco \& Thompson, 2005b). When someone does not have a script they lack a baseline for communicative behavior and are uncertain about how to interact with others who may be immersed in the script. Other bereaved parents are knowledgeable of this script and communication is less stifled under this situation. Another explanation for withdrawal may be their need for self-preservation (Dyregrov \& Dyregrov, 2008). Communicating with someone who has had a child die heightens one's own susceptibility to death. By avoiding talking with the bereaved the illusion of invulnerability to death is temporarily maintained. 


\section{Bereavement Trajectories}

Mancini and Bonanno (2009) propose a model of grief resilience wherein individual variables (e.g., personality, etc.) and exogenous resources (e.g., finances) influence two processes: an appraisal process and the degree of social support. The situational appraisal and the level of perceived social support (emotional and instrumental) will directly influence how they cope (emotional, cognitive, and behavioral dimensions of coping). These variables influence resilience. Coifman and Bonanno (2010) posit three trajectories of bereavement. The first is resilience or healthy adjustment where the bereaved are minimally affected by the loss. The second is called a recovery trajectory where the bereaved experience profound grief but are able to improve functioning within a few years. A final trajectory are those bereaved who suffer from chronic symptoms and are unable to return to a normal level of functioning without intervention (Coifman \& Bonanno, 2010). While parental grief is considered the ultimate deprivation, most of the participants in the present study could be primarily characterized by the recovery trajectory. Their traumatic bereavement experience may be characterized by expected anguish and despair, particularly for newer members; however, many of the more seasoned members have returned to some degree of "new normal," resuming work, family, and community responsibilities and rediscovering, slowly, joy and satisfaction in life.

\section{MISS Foundation Training and Philosophy}

All MISS Foundation support group facilitators are bereaved parents at least several years into their own losses. Most are former support group members and have learned through a modeling process how MISS Foundation sponsored meetings operate. Support group leaders participate in regular trainings to keep them up-to-date and aware of the latest research on parental bereavement. There is no specific training that guides facilitators to promote either restorative or loss-oriented disclosures (Stroebe \& Schut, 2010). The role of the facilitator is to guide the narratives such that everyone has an opportunity to share their story and to shepherd participants who may need extra support to clinical resources available to them in the community.

The mission of the leadership in the MISS Foundation is to help parents return to a level of pre-loss functioning or even to transcend their place in the world through service to others. The support group is just one facet of the resources offered by the MISS Foundation. Other services include bi-annual conferences for bereaved parents and professionals who care for them, 27 online support forums, HOPE (Helping Other Parents Endure) Mentors, professional trainings, and advocacy. 


\section{Future Research}

The Dual Processing Model (Stroebe \& Schut, 1999) provides an explanation for different trajectories of coping (process) following loss on consequences (outcomes) (Stroebe \& Schut, 2010). How people cope affects how well people adapt to the loss, and effective coping is associated with more positive health outcomes. Loss-oriented coping "refers to the bereaved person's concentration on, appraising and processing of some aspect of the loss experience itself . .." (Stroebe \& Schut, 2010, p. 277). Restoration-orientation "refers to the focus on secondary stressors that are also consequence of bereavement, reflecting a struggle to reorient oneself in a changed world without the deceased person" (Stroebe \& Schut, 2010, p. 277). The model suggests that adaptive adjustments to bereavement require an oscillation between loss-oriented and restorative-oriented coping. Previous research has identified gender differences in how people cope such that females follow a more loss-oriented path while males use a more restorative-orientation (Stroebe, Stroebe, \& Schut, 2001). While gender differences were not empirically examined in the present study, these tendencies appeared in the study. The fathers tended to talk about how coping affects them in their place of employment, how they are handling difficult finances, or how they are managing relations with their spouse. Mothers seemed to focus on visiting the cemetery, the details of the day their child died, and their emotional responses to the loss. Perhaps males use the group as a place to engage in more restorativeorientation coping and mothers as a safe place to focus on the death. This would be an interesting concentration area for future research.

\section{SUMMARY}

This research provides a next step in understanding the role of communication within a parental bereavement support group in the grief process. The parental bereavement support group provides participants with an opportunity to verbally think through the meaning of the death of their children and how it impacts their subsequent lives. Through dialogue participants are able to integrate new and shared understanding into their own lived stories. This combination of telling one's story, listening to other parent's stories, and integrating the two, results in meaning making for the bereaved so they may heal, going on to live productive and fulfilling lives. Based on the results of this study, it is important for clinicians and practitioners to understand the potential benefits of support groups manifested through the death story narrative, coping/ negotiating narrative, and connecting through communication with others narrative, making client referrals when appropriate and perhaps, even volunteering in their communities to bridge the gap between the practitioner and the bereaved parent population. 


\section{REFERENCES}

Anderson, H., \& Goolishian, H. (1988). Human systems as linguistic systems: Preliminary and evolving ideas about the implications for clinical theory. Family Process, 27, 371-393.

Arnold, J. H., \& Gemma, P. B. (1994). A child dies: A portrait of family grief (2nd ed.). Philadelphia, PA: The Charles Press Publisher.

Bambauer, K. Z., \& Prigerson, H. G. (2006). The Stigma Receptivity Scale and its association with mental health service use among bereaved older adults. Journal of Nervous and Mental Disease, 194(2), 139-141.

Barrera, M., D’Agostino, N., Schneiderman, G., Tallett, S., Spencer, L., \& Jovcevska, V. (2007). Patterns of parental bereavement following the loss of a child and related factors. Omega: Journal of Death and Dying, 55(2), 145-167.

Bosticco, C., \& Thompson, T. (2005a). The role of communication and story telling in the family grieving system. Journal of Family Communication, 5(4), 255-278.

Bosticco, C., \& Thompson, T. L. (2005b). Narratives and story-telling in coping with grief and bereavement. Omega, 51(1), 1-16.

Bowlby, J. (1969). Attachment and loss: Vol. 1 Attachment. Middlesex, England: Penguin.

Bowlby, J. (1973). Attachment and loss: Vol. 2 Separation: Anxiety and anger. New York: Basic Books.

Brockmeier, J., \& Harre, R. (1997). Narrative: Problems and promises of an alternative paradigm. Research on Language and Social Interaction, 30, 263-283.

Cacciatore, J. (2007). Effects of support groups on post traumatic stress responses in women experiencing stillbirth. Omega: Journal of Death and Dying, 55(1), 71-90.

Cacciatore, J., DeFrain, J., \& Jones, K. L. (2008). When a baby dies: Ambiguity and stillbirth. Marriage \& Family Review, 44(4), 439-454.

Cacciatore, J., Schnebly, S., \& Froen, J. F. (2009). The effects of social support on material anxiety and depression after stillbirth. Social Care in the Community, 17(2), 167-176.

Caserta, M. S., \& Lund, D. A. (1996). Beyond bereavement support group meetings: Exploring outside social contacts among the members. Death Studies, 20(6), 537-556.

Cluck, G. G., \& Cline, R. J. (1986). The circle of others: Self-help groups for the bereaved. Communication Quarterly, 34(3), 306-325.

Coifman, K. G., \& Bonanno, G. A. (2010). When distress does not become depression: Emotion context sensitivity and adjustment to bereavement. Journal of Abnormal Psychology, 119(3), 479-490.

Colvin, J., Chenoweth, L., Bold, M., \& Harding, C. (2004). Caregivers of older adults: Advantages and disadvantages of internet-based social support. Family Relations, $53,49-57$.

Corbin, J., \& Strauss, A. (1990). Grounded theory method: Procedures, canons, and evaluative criteria. Qualitative Sociology, 13, 3-21.

Dyregrov, K., \& Dyregrov, A. (2008). Effective grief and bereavement support: The role of family, friends, colleagues, schools and support professionals. Philadelphia, PA: Jessica Kingsley Publishers.

Fisher, W. R. (1984). Narration as a human communication paradigm: The case of public moral argument. Communication Monographs, 51, 1-22.

Fisher, W. R. (1987). Human communication as narration: Toward a philosophy of reason, value, and action. Columbia, SC: University of South Carolina. 
Foss, S. K. (1989). Narrative criticism. In Rhetorical criticism: Exploration and practice. Prospect Heights, IL: Waveland Press.

Freedman, J., \& Combs, G. (1996). The social construction of preferred realities. New York: W. W. Norton \& Company.

Glaser, B. G., \& Strauss, A. L. (1967). The discovery of grounded theory: Strategies for qualitative research. New York: Aldine de Gruyter.

Graves, D. (2009). Talking with bereaved people: An approach for structured and sensitive Communication. Philadelphia, PA: Jessica Kingsley Publishers

Griffin, E. M. (2009). A first look at communication theory (7th ed.). Boston, MA: McGraw-Hill.

Gudmundsdottir, M., \& Chesla, C. A. (2006). Building a new world: Habits and practices of healing following the death of a child. Journal of Family Nursing, 12(2), 143-164.

Harvey, J. H. (1996). Embracing their memory: Loss and the social psychology of storytelling. Needham Heights, MA: Allyn \& Bacon.

Hastings, S. O., Musambira, G. W., \& Hoover, J. D. (2007). Community as a key to healing after the death of a child. Communication \& Medicine, 4(2), 153-163.

Hopmeyer, E., \& Werk, A. (1994). A comparative study of family bereavement groups. Death Studies, 18(3), 243-256.

Kamm, S., \& Vandenberg, B. (2001). Grief communication, grief reactions and marital satisfaction in bereaved parents. Death Studies, 25(7), 569-582.

Katz-Wise, S. L., Priess, H. A., \& Hyde, J. S. (2010). Gender-role attitudes and behavior across the transition to parenthood. Developmental Psychology, 46(1), 18-28.

Keesee, N. J., Currier, J. M., \& Neimeyer, R. A. (2008). Predictors of grief following the death of one's child: The contribution of finding meaning. Journal of Clinical Psychology, 64(10), 1145-1163.

Klass, D. (1988). Parental grief: Solace and resolution. New York: Springer.

Klass, D. (1993). Solace and immortality: Bereaved parents' continuing bond with their children. Death Studies, 17, 343-368.

Klass, D. (1997). The deceased child in the psychic and social worlds of bereaved parents during the resolution of grief. Death Studies, 21, 147-175.

Klass, D. (1999). The spiritual lives of bereaved parents. Philadelphia: Brunner/Mazel.

Levy, L. H., \& Derby, J. F. (1992). Bereavement support groups: Who joins; who does not; and why. American Journal of Community Psychology, 20(5), 649-662.

Levy, L. H., Derby, J. F., \& Martinkowski, K. S. (1993). Effects of membership in bereavement support groups on adaptation to conjugal bereavement. American Journal of Community Psychology, 21(3), 361-381.

Mancini, A. D., \& Bonanno, G. A. (2009). Predictors and parameters of resilience to loss: Toward an individual differences model. Journal of Personality, 77(6), 1805-1831.

Maruyama, N. C., \& Atencio, C. V. (2008). Evaluating a bereavement support group. Palliative \& Supportive Care, 6(1), 43-49.

Mitchell, A. M., Gale, D. D., Garand, L., \& Wesner, S. (2003). The use of narrative data to inform the psychotherapeutic group process with suicide survivors. Issues in Mental Health Nursing, 24(1), 91-106.

Murphy, S. A., Johnson, L. C., \& Lohan, J. (2003). Finding meaning in a child's violent death: A five-year prospective analysis of parents' personal narratives and empirical data. Death Studies, 27(5), 381-404. 
Musambira, G. W., Hastings, S. O., \& Hoover, J. D. (2006). Bereavement, gender, and cyberspace: A content analysis of parents' memorials to their children. Omega: Journal of Death and Dying, 5(4), 263-279.

Monk, G., Winslade, J., Crocket, K., \& Epston, D. (1997). Narrative Therapy in Practice. San Francisco, CA: Jossey-Bass.

Pare, D. A. (1995). Of families and other cultures: The shifting paradigm of family therapy. Family Process, 21, 1-19.

Parry, A., \& Doan, R. E. (1994). Story re-visions: Narrative therapy in the postmodern world. New York: Guilford Press.

Picton, C., Cooper, B. K., Close, D., \& Tobin, J. (2001). Bereavement support groups: Timing of participation and reasons for joining. Omega: Journal of Death and Dying, 43(3), 247-258.

Reif, L. V., Patton, M. J., \& Gold, P. B. (1995). Bereavement, stress, and social support in members of a self-help group. Journal of Community Psychology, 23(4), 292-306.

Reilly-Smorawski, B., Armstrong, A. V., \& Catlin, E. A. (2002). Bereavement support for couples following death of a baby: Program development and 14-year exit analysis. Death Studies, 26(1), 21-37.

Riches, G., \& Dawson, P. (1996). Communities of feeling: The culture of bereaved parents. Mortality, 1(2), 143-161.

Riley, L. P., LaMontagne, L. L., Hepworth, J. T., \& Murphy, B. A. (2007). Parental grief responses and personal growth following the death of a child. Death Studies, 31, 277-299.

Rosenblatt, P. C. (2000). Parent grief: Narratives of loss and relationship. Philadelphia, PA: Brunner/Mazel.

Rosof, B. D. (1994). The worst loss: How families heal from the death of a child. New York: Henry Holt and Company.

Strauss, A., \& Corbin, J. (1990). Basics of qualitative research: Grounded theory procedures and techniques. Newbury Park, CA: Sage.

Strauss, A., \& Corbin, J. (1994). Grounded theory methodology: An overview. In N. K. Denzin \& Y. S. Lincoln (Eds.), Handbook of qualitative research (pp. 273-285). Thousand Oaks, CA: Sage.

Strauss, A., \& Corbin, J. (1998). Basics of qualitative research: Techniques and procedures for developing grounded theory. Thousand Oaks, CA: Sage.

Stroebe, M. S., \& Schut, H. (1999). The dual processing model of coping with bereavement: Rationale and description. Death Studies, 23, 197-224.

Stroebe, M., \& Schut, H. (2010). The dual process model of coping with bereavement: A decade on. Omega: Journal of Death and Dying, 61(4), 273-289.

Stroebe, M., Stroebe, W., \& Schut, H. (2001). Gender differences in adjustment to bereavement: An empirical and theoretical review. Review of General Psychology, $5,62-83$.

Stylianos, S. K., \& Vachon, M. L. S. (1993). The role of social support in bereavement. In M. Stroebe, W. Stroebe, \& R. O. Hanssen (Eds.), Handbook of bereavement: Theory research and intervention (pp. 397-410). Cambridge, England: Cambridge University Press.

Tedeschi, R. G., \& Calhoun, L. G. (1993). Using the support group to respond to the isolation of bereavement. Journal of Mental Health Counseling, 15(1), 47-54. 
160 / UMPHREY AND CACCIATORE

Thuen, F. (1995). Satisfaction with bereavement support groups: Evaluation of the Norwegian Bereavement Care Project. Journal of Mental Health, 4(5), 499-510.

Toller, P. W. (2005). Negotiation of dialectical contradictions by parents who have experienced the death of a child. Journal of Applied Communication Research, 33(1), 46-66.

Toller, P. W. (2008). Bereaved parents' negotiation of identity following the death of a child. Communication Studies, 59(4), 306-321.

Wright, K. B. (1997). Shared ideology in Alcoholics Anonymous: A grounded theory approach. Journal of Health Communication, 2, 83-99.

Direct reprint requests to:

Laura R. Umphrey, Ph.D.

School of Communication

P.O. Box 5619

Building \#16 Tormey Avenue

Northern Arizona University

Flagstaff, AZ 86011-5619

e-mail: laura.umphrey@nau.edu 